\title{
SUS Para Todos, Para Pobres ou Para Ninguém? A visão de Estudantes de Educação Física
}

\author{
Joamara de Oliveira Pimentel, ${ }^{1}$ Ana Maria Rigo Silva, ${ }^{2}$ \\ Lucélia Justino Borges, ${ }^{3}$ Silvano da Silva Coutinho, ${ }^{4}$ Mathias Roberto Loch ${ }^{2}$
}

\section{RESUMO}

Objetivou-se verificar a visão de estudantes de Educação Física sobre para quem deveria ser o direito ao acesso ao Sistema Único de Saúde (SUS) ("para todos", "para pobres" ou "para ninguém") de maneira geral e em ações/serviços específicos. 349 estudantes (216 ingressantes e 133 concluintes) de três universidades públicas do Paraná responderam um questionário semiestruturado. As questões principais avaliaram a visão dos estudantes de Educação Física sobre o princípio da universalidade de um modo geral (a partir de uma pergunta sobre como deveria ser o direito ao acesso) e para 11 serviços/ações específicas. Na análise dos dados foi utilizada a análise de frequência e o teste qui-quadrado $(p \leq 0,05)$. A maioria $(85,4 \%)$ considerou que o acesso ao SUS deveria ser "para todos" (sem diferença entre ingressantes e concluintes, $p=0,090$ ), enquanto 12,9\% consideraram que deveria ser "para pobres" e 1,7\% "para ninguém". Quanto ao acesso de forma mais específica, os concluintes apresentaram mais respostas "para todos" sobre para quem deveria ser o acesso aos 11 serviços/ações oferecidos pelo SUS que os ingressantes. Conclui-se que um percentual elevado de estudantes de Educação Física considera que o acesso ao SUS deve ser universal, mas parece prevalecer uma visão limitada sobre os serviços/ações que devem ser "para todos".

Palavras-chave: Sistema Único de Saúde; educação física e treinamento; universalização da saúde; integralidade em saúde.

\section{UNIFIED HEALTH SYSTEM FOR EVERYONE, FOR THE POOR OR FOR ANYONE?} THE VIEW OF PHYSICAL EDUCATION STUDENTS

\section{ABSTRACT}

The objective was to verify the view of physical education students about who should have the right to access Brazilian Health System (SUS) ("for all, "for the poor" or "for no one") in general and in specific actions/services. 349 students (216 freshman and 133 graduates) from three public universities in Paraná answered a semi-structured questionnaire. The main questions assessed the Physical Education students view of the principle of universality, in general (from a general question about what access should be) and for 11 specific services/actions. In the data analysis, frequency analysis and the chi-square test $(p \leq 0,05)$ were used. The majority $(85,4 \%)$ considered that access to SUS should be "for everyone" (with no difference between freshmen and graduating students, $p=0,090$ ), while $12,9 \%$ considered that it should be "for the poor" and 1,7\% "for no one". As to access in a more specific way, the graduates presented more responses "for all" about who should have access to the 11 services/actions offered by SUS than those freshman. It is concluded that a high percentage of physical education students considers that access to SUS should be universal, but a limited view on the services/actions that should be "for all".

Keywords: Brazilian Health System; physical education and training; universalization of health, integrality in health.

RECEBIDO EM: 19/10/2020

MODIFICAÇÕES SOLICITADAS EM: 10/12/2020

ACEITO EM: 22/12/2020

\footnotetext{
${ }_{1}$ Autora correspondente. Universidade Estadual de Londrina - UEL. Rodovia Celso Garcia Cid, PR-445, Km 380. Londrina/PR, Brasil. CEP 86057-970. http://lattes.cnpq.br/1392342522122545. https://orcid.org/0000-0002-3023-3273. joamarauel@hotmail.com

2 Universidade Estadual de Londrina - UEL. Londrina/PR, Brasil.

${ }^{3}$ Universidade Federal do Paraná - UFPR. Curitiba/PR, Brasil.

${ }^{4}$ Universidade Estadual do Centro-Oeste - Unicentro. Guarapuava/PR, Brasil.
} 


\section{INTRODUÇÃO}

Com a Constituição Federal de 1988, influenciada pelo Movimento da Reforma Sanitária, o Brasil optou por um sistema de saúde que nasceu sob uma perspectiva ampliada sobre o tema, tendo como um de seus princípios finalísticos a universalidade no acesso, entendendo a saúde como direito de todos e dever do Estado (PAIM, 2018). A universalidade é o princípio do Sistema Único de Saúde (SUS) que legitima o direito ao acesso a ações e serviços de saúde irrestritamente e sem qualquer tipo de discriminação (GIOVANELLA et al., 2018).

O conceito de direito ao acesso a serviços de saúde é construído historicamente e é relativamente recente. A ideia de universalização da assistência para a saúde das populações como proteção social surgiu após a Segunda Guerra Mundial (MARQUES, 2016). Em diversos países há sistemas universais de saúde que visam a assegurar o acesso universal à saúde como premissa de cidadania (GIOVANELLA et al., 2018; MARQUES, 2016). A visão que uma sociedade tem sobre saúde está ligada a contextos amplos de acordo com questões históricas e culturais, e abrange o presente e o passado de suas configurações sociais, econômicas e políticas (MINAYO, 2006), influenciando a organização do seu sistema de saúde.

Atualmente, inclusive em razão da pressão exercida pelo setor privado, reforça-se a ideia de saúde como mercadoria, reduzindo cidadãos à condição de consumidores e incentivando o Estado a restringir o acesso aos serviços públicos apenas àqueles que não podem pagar por serviços privados (PAIM, 2018). Este movimento é reforçado internacionalmente por iniciativas, como o modelo de atenção à saúde denominado "cobertura universal em saúde", incentivado pelo Banco Mundial, e que aparece em relatórios da Organização Mundial da Saúde (OMS) como alternativa ao financiamento dos serviços de saúde, sendo excludente e não necessariamente os serviços seriam oferecidos pelo Estado, e tem como objetivo cobrir cestas de serviços à determinada parcela da população, o que pode levar à solidificação de desigualdades (NORONHA, 2013; GIOVANELLA et al., 2018; RIZZOTTO, 2018).

No Brasil, a mercantilização da saúde vem acontecendo por meio das políticas de austeridade fiscal e também influenciada por órgãos internacionais. Em 2016, a Emenda Constitucional 95 limitou os investimentos na saúde para os 20 anos seguintes, comprometendo a viabilização da seguridade social no país (GIOVANELLA et al., 2018). Em novembro de 2019, o governo federal aprovou medidas alterando o financiamento da Atenção Primária a Saúde, extinguindo o recurso fixo da atenção básica, que, desde 1997, era passado diretamente da União aos municípios (BRASIL, 2019). Estas medidas colocam em risco ações e serviços e criam uma seletividade na atenção, enfraquecendo a visão de universalidade e fortalecendo uma visão de SUS "para pobres".

O SUS vai além do acesso universal à saúde, e isso é evidente em outro de seus princípios finalísticos: a integralidade. Este princípio implica considerar os diversos aspectos que influenciam a saúde individual e coletiva, assegurando perspectivas de proteção, promoção, reabilitação, prevenção, tratamento e

Editora Unijuí - Revista Contexto \& Saúde - ISSN 2176-7114 - v. 21, n. 43, jul./set. 2021 
cura. O objetivo da integralidade é a ampliação dos serviços e ações em saúde de maneira intersetorial, compreendendo o ser humano como um todo, complexo e não fragmentado (VASCONCELOS; PASCHE, 2006). Assim, este princípio possibilitou a inserção de diferentes áreas profissionais no setor da saúde pública no Brasil, inclusive a Educação Física (CNS, 1997).

Especialmente a partir da primeira década dos anos 2000, a Educação Física passou a atuar de forma mais evidente no SUS, uma vez que, antes deste período, havia somente algumas experiências pontuais ou programas de atividade física sem um vínculo mais direto com o SUS (ANDRADE, 2011). Logo, vale mencionar marcos importantes, como a publicação da primeira versão da Política Nacional de Promoção da Saúde em 2006, que tem como um de seus eixos prioritários as práticas corporais/atividade física (PCAF) (BRASIL, 2014), além da criação do Núcleo de Apoio à Saúde da Família - Nasf (atual Nasf-AB - Núcleo Ampliado de Saúde da Família e Atenção Básica) em 2008 (BRASIL, 2008) e a alteração da Lei 8.080/90 em 2013, com a inclusão da atividade física como condicionante e determinante de saúde (BRASIL, 2013).

Com isso, alguns cursos de Educação Física iniciaram um processo de redirecionamento da formação acadêmica, observando as condições amplas que interferem na saúde das populações, tendo maior atenção ao sistema de saúde brasileiro (NEVES et al., 2015). Alguns autores, porém, caracterizam a formação na Educação Física para a atuação no SUS como incipiente e limitada (NEVES et al., 2015; CANDIDO; ROSSIT; OLIVEIRA, 2018; LOCH et al., 2018; COSTA, 2019).

Algumas pesquisas têm buscado compreender concepções, ideias e dificuldades sobre a atuação do profissional de Educação Física na saúde pública/ coletiva (OLIVEIRA, 2018; NOGUEIRA; BOSI, 2017; LOCH; DIAS; RECH, 2019; FERREIRA et al., 2019). Tais investigações auxiliam a reflexão sobre a prática deste profissional no SUS e contribuem para a construção de uma visão mais ampliada e crítica dos cursos de formação profissional em relação à atuação neste campo (NEVES et al., 2015; COSTA, 2019). São poucos, entretanto, os estudos que têm como foco a visão dos estudantes sobre aspectos relativos ao SUS.

Assim, considerando as especificidades da Educação Física, sua recente "entrada" no contexto do SUS, a relevância de se conhecer melhor a visão dos diversos atores a respeito de elementos que compõem o SUS e a atuação profissional em seu contexto, é importante conhecer a visão que os graduandos em Educação Física têm sobre o SUS, de maneira geral e em ações específicas, para a construção de uma visão mais ampla e crítica dos cursos de formação em relação à atuação deste profissional na saúde pública/coletiva, além de contribuir para o âmbito de práticas e saberes das áreas de Saúde Coletiva e Educação Física. Dado este contexto, o objetivo desta pesquisa foi verificar a visão de estudantes do curso de bacharelado em Educação Física de três universidades públicas do Paraná sobre quem deveria ter direito ao acesso ao SUS de maneira geral e em ações/serviços específicos. 


\section{MÉTODOS}

Trata-se de um estudo transversal, descritivo e quantitativo com estudantes ingressantes em 2019 e concluintes do mesmo ano, dos cursos de Bacharelado em Educação Física de três universidades públicas do Paraná. Os procedimentos do estudo seguiram as normas da Resolução do Conselho Nacional de Saúde 466/12 e foram aprovados pelo Comitê de Ética em Pesquisa das instituições de Ensino Superior envolvidas no estudo: Universidade Estadual de Londrina - UEL (CAAE 07939019.6.0000.5231), Universidade Federal do Paraná - UFPR (CAAE 07939019.6.3002.0102) e Universidade Estadual do Centro-Oeste - Unicentro (CAAE 07939019.6.3003.0106).

As três universidades incluídas no estudo foram a UFPR Campus Curitiba, que conta com 75 vagas para ingresso no curso, em turmas de período integral (BRASIL, 2020a) e duas universidades estaduais: uma situada na região norte do Estado, na cidade de Londrina - a UEL -, com 180 vagas divididas em três turmas matutinas e três noturnas (UEL, 2018), e a Unicentro na região centro-sul do Estado, Campus de Guarapuava, com 40 vagas em uma turma de período integral (UNICENTRO, 2019).

Para a realização desta pesquisa entrou-se em contato com a coordenação dos respectivos cursos para explicar os objetivos e métodos desta, solicitando a anuência para a realização do estudo em suas respectivas instituições. Após o aceite, foi feito contato com professores responsáveis pelas turmas do primeiro e do último ano para a autorização da coleta de dados em sala de aula.

Com os ingressantes a coleta ocorreu entre o final de março e o começo de abril de 2019, buscando-se verificar a visão dos estudantes com a menor influência possível da Graduação, propiciando maior aproximação com a visão dos estudantes ao entrarem na universidade. A coleta de dados dos concluintes foi realizada entre os meses de agosto e setembro de 2019, dependendo do calendário de cada universidade envolvida, buscando-se avaliá-los após algumas semanas do início do último semestre do curso, para que os dados refletissem a visão destes estudantes ao final do curso.

Todos os estudantes presentes em sala de aula no momento da coleta foram convidados a participar da pesquisa, buscando fazer um censo com os estudantes e, por isso, não foram utilizadas técnicas de amostragem probabilística. Seguiu-se com as informações sobre os objetivos e procedimentos necessários, e aqueles que aceitaram participar assinaram o Termo de Consentimento Livre e Esclarecido.

Entre os ingressantes, 238 estudantes responderam o questionário (38 da UFPR, 166 da UEL e 34 da Unicentro), e entre os concluintes, 135 (41 da UFPR, 73 da UEL e 21 da Unicentro). Como critério de exclusão foram observados os estudantes ingressantes que estavam repetindo o primeiro ano totalmente ou retidos em alguma disciplina, pois o objetivo do trabalho foi analisar o momento de entrada no curso com a menor influência possível da universidade na vida desses estudantes. Dos 373 estudantes que responderam ao questionário, 17 foram excluídos pelo critério estabelecido. Houve cinco "perdas" entre os estudantes que não responderam a seção de questões sobre informações demográfi-

Editora Unijuí - Revista Contexto \& Saúde - ISSN 2176-7114 - v. 21, n. 43, jul./set. 2021 
cas (quatro entre os ingressantes e um entre os concluintes) e duas em razão da não resposta à questão central do trabalho (sobre como deveria ser o acesso aos SUS, de maneira geral). Assim, para este estudo foram considerados dados de 349 estudantes, 216 ingressantes e 133 concluintes.

Foi elaborado um questionário semiestruturado, que contou com as seguintes seções: Percepções sobre o SUS, Perspectivas de atuação profissional e Informações sociodemográficas. As variáveis centrais desta pesquisa envolveram duas questões relacionadas ao acesso ao SUS. A primeira referente ao acesso de maneira geral, buscando compreender a visão dos estudantes sobre o princípio da universalidade. A segunda relacionou o acesso de forma mais específica, elencando 11 serviços/ações oferecidos pelo SUS, para compreender a visão dos estudantes sobre a integralidade e verificar como eles consideram que deveria ser a abrangência do SUS.

Na primeira questão sobre o acesso buscou-se avaliar, de maneira geral, a visão dos estudantes sobre quem deveria ter direito ao acesso ao SUS. Para isso, cada aluno deveria considerar o seguinte enunciado: "Em geral, você acredita que o Brasil (assinale somente uma alternativa)" e escolher umas das seguintes opções:

1) Não deveria ter serviços públicos de saúde e cada pessoa deveria arcar com os custos de seus atendimentos em saúde.

2) Deveria ter serviços públicos de saúde para atender as pessoas que não podem pagar por atendimentos de saúde, enquanto as pessoas com condições financeiras deveriam pagar planos privados de saúde ou pagar individualmente pelos serviços de saúde;

3) Deveria investir na construção de serviços públicos de saúde que atendessem com qualidade todas as pessoas, independente da classe econômica.

A primeira opção buscou refletir a visão de SUS "para ninguém", a segunda de SUS "para pobres" e a terceira de SUS "para todos". Para elaborar estas alternativas de resposta, algumas etapas foram realizadas buscando seu aprimoramento, de modo que as opções fossem claras e refletissem a visão de cada aluno.

Entre as etapas para esta construção foi solicitada a avaliação das opções por um grupo de estudos relacionados à temática Educação Física e Saúde Coletiva da UEL, que contava com alunos de Graduação e Pós-Graduação das duas áreas; a realização de um trabalho de conclusão de curso com ingressantes e concluintes de uma das universidades (GONÇALVES, 2016); consulta a 12 professores doutores das áreas de Educação Física ou Saúde Coletiva, com produção na área da Saúde Coletiva, por meio de questionário eletrônico. Este questionário abrangeu perguntas quanto à clareza e adequação das opções, bem como um espaço para eventuais sugestões de melhoria da redação das opções. Também foi realizado um pré-teste do instrumento com 19 estudantes do segundo ano do curso de Bacharelado em Educação Física da UEL, com objetivo de verificar o tempo necessário para aplicação do instrumento e a compreensão dos estudantes. Nesta etapa, observou-se que o tempo médio de aplicação do instrumento 
no pré-teste foi de 20 minutos, e os estudantes não referiram dificuldades no preenchimento do instrumento.

Para a segunda questão, sobre o acesso ao SUS de maneira mais específica, foi elaborado um quadro com 11 ações/serviços oferecidos pelo SUS para que cada estudante assinalasse se, na sua visão, cada ação/serviço deveria ser oferecido "para todos", "para quem não pode pagar" (para pobres) ou "para ninguém", seguindo a mesma lógica da questão anterior (geral), mas desta vez com cada serviço/ação de maneira separada. Os seguintes serviços/ ações foram apresentados em ordem alfabética: acompanhamento de pessoas com doenças crônicas; acompanhamento psicológico; acompanhamento de gestantes (pré-natal); atendimento domiciliar para pessoas com dificuldade de locomoção; atendimento odontológico; atendimento de urgência e emergência; fisioterapia; fornecimento de medicamentos; programas de práticas corporais/atividade física (PCAF); vacinação para crianças e adolescentes e vacinação para adultos.

Foram incluídas variáveis de características demográficas (sexo, idade, raça/cor, se cursou Ensino Médio em escola pública ou privada e escolaridade dos pais); avaliação do SUS e acesso aos serviços de saúde (se tinham plano privado de saúde, se utilizou os serviços do SUS nos últimos 12 meses).

Os dados foram duplamente digitados, com correção das inconsistências encontradas. As análises foram realizadas no Programa SPSS versão 19.0., por meio de estatística descritiva e teste qui-quadrado, adotando-se um nível de significância de 5\%.

\section{RESULTADOS}

A Tabela 1 apresenta as características demográficas, perfil de utilização e avaliação sobre o SUS, conhecimento sobre possibilidades de atuação do profissional de Educação Física no SUS e perspectivas de atuação profissional no SUS dos estudantes ingressantes e concluintes dos cursos de Bacharelado em Educação Física. Considerando toda a amostra, observou-se que a maioria era do sexo masculino (65,9\%), se autodeclarou de cor amarela/branca $(70,2 \%)$, fez o Ensino Médio totalmente em escola pública $(66,8 \%)$ e informou que os pais não tinham Ensino Superior (59,4\% das mães e $70,8 \%$ dos pais). Não foram observadas diferenças significativas nas características demográficas de ingressantes e concluintes. Quanto à avaliação sobre o SUS, 45,4\% avaliaram como regular, e, sobre a utilização, a maioria mencionou que recebeu atendimento (ou acompanhou alguém) no SUS nos últimos 12 meses $(68,4 \%)$ e 53,4\% declararam ter plano privado de saúde. Quando comparados ingressantes e concluintes, houve maior proporção de concluintes que consideraram o SUS como bom/muito bom $(p<0,001)$, assim como maior proporção de concluintes que referiram receber atendimento (ou acompanhar alguém) no SUS nos últimos 12 meses ( $p=0,011$ ). Na questão relacionada a ter ou não ter plano privado de saúde, não houve diferença entre os resultados de ingressantes e concluintes.

Editora Unijuí - Revista Contexto \& Saúde - ISSN 2176-7114 - v. 21, n. 43, jul./set. 2021 
Tabela 1 - Características demográficas, perfil de utilização e avaliação sobre o SUS dos estudantes ingressantes e concluintes

\begin{tabular}{lccccccc}
\hline VARIÁVEIS & \multicolumn{2}{c}{ TODOS } & \multicolumn{1}{l}{ INGRESSANTES } & CONCLUINTES & p* \\
\hline \multirow{2}{*}{ Todos } & $\mathbf{n}$ & $\mathbf{\%}$ & $\mathbf{n}$ & $\mathbf{\%}$ & $\mathbf{n}$ & $\mathbf{\%}$ & \\
& 349 & 100 & 216 & 61,9 & 133 & 38,1 &
\end{tabular}

\section{Sexo}

Feminino

Masculino

$\begin{array}{ccc}119 & 34,1 & 66 \\ 230 & 65,9 & 150\end{array}$

$30,6 \quad 53$

39,8

$69,4 \quad 80$

60,2

0,075

\section{Raça/cor}

Amarela/branca

$\begin{array}{ccc}245 & 70,2 & 144 \\ 104 & 29,8 & 72\end{array}$

Parda/preta

66,7

$33,3 \quad 32 \quad 24,1$

0,066

\section{Escola onde fez Ensino Médio}

Totalmente Particular

$23366,8 \quad 136$

63,0

97

73,0

Parcial pública/particular

$99 \quad 28,4 \quad 66$

30,5

33

24,8

$\begin{array}{llllll}17 & 4,9 & 14 & 6,5 & 3 & 2,2\end{array}$

0,074

\section{Escolaridade da mãe}

Até Ensino Médio

completo

$\begin{array}{lllllll}205 & 59,4 & 119 & 56,1 & 86 & 64,7 & \\ 140 & 40,6 & 93 & 43,9 & 47 & 35,3 & \end{array}$

Ensino Superior

\section{Escolaridade do pai}

Até Ensino Médio

completo

$\begin{array}{lllllll}240 & 70,8 & 146 & 68,9 & 94 & 74,0 & \\ 99 & 29,2 & 66 & 31,1 & 33 & 26 & \end{array}$

Ensino Superior

Como avalia o SUS

Muito Bom/Bom

$\begin{array}{ccc}90 & 26,7 & 31 \\ 153 & 45,4 & 100 \\ 94 & 27,9 & 77\end{array}$

$\begin{array}{ll}15,0 & 59 \\ 48,0 & 53 \\ 37,0 & 17\end{array}$

45,7

Regular

Ruim/muito ruim

Nos últimos 12 meses usou ou acompanhou alguém em um atendimento realizado no SUS

\begin{tabular}{lccccccc} 
Sim & 238 & 68,4 & 137 & 63,4 & 101 & 76,5 & 0,011 \\
Não & 110 & 31,6 & 79 & 36,6 & 31 & 23,5 & \\
& & & & & & & \\
\multicolumn{2}{l}{ Tem plano privado de saúde } & & & & & & \\
Sim & 186 & 53,4 & 118 & 54,9 & 68 & 51,1 & 0,495 \\
Não & 162 & 46,6 & 97 & 45,1 & 65 & 48,9 & 0,4 \\
\hline
\end{tabular}

* Relativo ao valor teste qui-quadrado em relação às diferenças entre ingressantes e concluintes. Fonte: Resultados do estudo.

A Tabela 2 apresenta a proporção de estudantes (total e segundo variáveis demográficas), de avaliação e utilização do SUS, que consideraram que o acesso 
ao SUS deveria ser "para ninguém", "para pobres" e "para todos" em ingressantes e concluintes. A maioria dos ingressantes e dos concluintes considerou que 0 acesso deveria ser "para todos", não havendo, de maneira geral, diferença entre ingressantes e concluintes $(p=0,090)$. Quando analisadas de maneira estratificada segundo as variáveis independentes da Tabela, observou-se que nas mulheres a proporção das que consideraram que o SUS deveria ser "para todos" foi maior entre as concluintes ( $92,5 \%$ das concluintes e $77,3 \%$ das ingressantes; $p=0.025$ ) e também foi maior nos concluintes esta proporção entre aqueles estudantes que tinham cursado todo seu Ensino Médio em escolas públicas (90,7\% nos concluintes e $78,0 \%$ nos ingressantes; $p=0,010$ ) e nos que referiram que o pai não tinha curso superior ( $90,4 \%$ entre os concluintes e $80,8 \%$ nos ingressantes; $p=0,044)$. A opção "SUS para ninguém" foi indicada por poucos ingressantes e concluintes (1,8\% e 1,5\% respectivamente), e na opção "SUS para pobres" as proporções foram de $15,3 \%$ entre os ingressantes e 9,0\% entre os concluintes.

Tabela 2 - Proporção de estudantes ingressantes e concluintes, total e segundo características demográficas e de perfil de utilização e avaliação sobre o SUS, que consideram que o acesso ao SUS deveria ser "para ninguém", "para pobres" e "para todos". (Total de ingressantes $=216$. Total de concluintes $=133$ )

\begin{tabular}{|c|c|c|c|c|c|c|c|}
\hline \multirow[t]{2}{*}{ Variáveis } & \multicolumn{2}{|c|}{ SUS para Ninguém } & \multicolumn{2}{|c|}{ SUS para Pobres } & \multicolumn{3}{|c|}{ SUS para Todos } \\
\hline & Ingressantes & Concluintes & Ingressantes & Concluintes & Ingressantes & Concluintes & $\mathrm{P}^{*}$ \\
\hline & $\%$ & $\%$ & $\%$ & $\%$ & $\%$ & $\%$ & \\
\hline Todos & 1,8 & 1,5 & 15,3 & 9,0 & 82,9 & 89,5 & 0,090 \\
\hline \multicolumn{8}{|l|}{ Sexo } \\
\hline Feminino & 1,5 & 0 & 21,2 & 7,5 & 77,3 & 92,5 & 0,025 \\
\hline Masculino & 2,0 & 2,5 & 12,7 & 10,0 & 85,3 & 87,5 & 0,651 \\
\hline \multicolumn{8}{|l|}{ Raça/Cor } \\
\hline Amarela/Branca & 1,4 & 2,0 & 15,3 & 9,9 & 83,3 & 88,1 & 0,298 \\
\hline Parda/Preta & 2,8 & 0 & 15,3 & 6,2 & 81,9 & 93,8 & 0,114 \\
\hline \multicolumn{8}{|c|}{ Escola onde cursou Ensino Médio } \\
\hline Totalmente Pública & 2,9 & 1,0 & 19,1 & 8,3 & 78,0 & 90,7 & 0,010 \\
\hline Totalmente & 0 & 3,0 & 10,6 & 12,1 & 89,4 & 84,9 & 0,514 \\
\hline \multicolumn{8}{|l|}{ Particular } \\
\hline Parcial Pública/ & 0 & 0 & 0 & 0 & 100 & 100 & - \\
\hline \multicolumn{8}{|l|}{ Particular } \\
\hline \multicolumn{8}{|l|}{ Escolaridade do Pai } \\
\hline $\begin{array}{l}\text { Até Ensino Médio } \\
\text { completo }\end{array}$ & 1,4 & 2,1 & 17,8 & 7,5 & 80,8 & 90,4 & 0,044 \\
\hline Ensino Superior & 3 & 0 & 9,1 & 15,2 & 87,9 & 84,8 & 0,674 \\
\hline \multicolumn{8}{|l|}{ Escolaridade da Mãe } \\
\hline $\begin{array}{l}\text { Até Ensino Médio } \\
\text { completo }\end{array}$ & 3,4 & 2,3 & 17,6 & 9,3 & 79,0 & 88,4 & 0,078 \\
\hline Ensino Superior & 0 & 0 & 12,9 & 8,5 & 87,1 & 91,5 & 0,440 \\
\hline \multicolumn{8}{|c|}{ Tem Plano Privado de Saúde } \\
\hline Sim & 2,5 & 2,9 & 14,4 & 7,4 & 83,1 & 89,7 & 0,215 \\
\hline Não & 1 & 0 & 16,5 & 10,8 & 82,5 & 89,2 & 0,235 \\
\hline \multicolumn{8}{|l|}{ Como Avalia o SUS } \\
\hline Muito Bom/Bom & 0 & 0 & 12,9 & 8,5 & 87,1 & 91,5 & 0,506 \\
\hline Regular & 0 & 0 & 16,0 & 9,4 & 84,0 & 90,6 & 0,261 \\
\hline
\end{tabular}


Nos últimos 12 meses usou ou acompanhou alguém em um atendimento realizado no SUS

\begin{tabular}{lccccccc} 
Sim & 1,5 & 0 & 13,1 & 10,9 & 85,4 & 89,1 & 0,401 \\
Não & 2,5 & 6,5 & 19 & 3,2 & 78,5 & 90,3 & 0,147 \\
\hline
\end{tabular}

* Relativo ao valor teste qui-quadrado em relação às diferenças entre ingressantes e concluintes em cada categoria das variáveis na proporção de resposta de SUS "para todos".

A Tabela 3 apresenta as proporções de estudantes ingressantes e concluintes que consideraram que o acesso a cada um dos 11 serviços/ações elencados neste estudo deveria ser "para ninguém", "para pobres" ou "para todos". Para todos os serviços a maioria dos estudantes considerou que deveriam ser oferecidos "para todos". A ação/serviço com menor proporção de "para todos" foi "fisioterapia" (58,2\% entre ingressantes e 69,9\% entre concluintes). Vale mencionar que o atendimento odontológico e o fornecimento de medicamentos tiveram frequência menor de $70 \%$ entre estudantes ingressantes que consideraram que deveria ser "para todos". Entre os concluintes, o único serviço que teve frequência menor que $70 \%$ de respostas "para todos" foi fisioterapia. Por outro lado, a ação/serviço com maior proporção de ingressantes e concluintes que considerou que deveria ser de acesso "para todos" foi serviços de urgência e emergência (94,9\% e 96,2\% respectivamente). Quando observadas as diferenças nas proporções de resposta de acesso "para todos" em cada ação/ serviço entre ingressantes e concluintes, observou-se diferença em relação ao acompanhamento psicológico $(p=0,033)$, atendimento domiciliar para pessoas com dificuldade de locomoção $(p=0,045)$ e programas de PCAF $(p=0,047)$, sendo maior, nestas ações/serviços, a proporção de estudantes concluintes que consideraram que deveria ser de acesso "para todos". Além disso, os resultados mostraram que a maior proporção de ingressantes (39\%) e concluintes (29,3\%) que optaram pela resposta "para pobres" nesta questão foi para o serviço/ação fisioterapia.

Tabela 3 - Proporção de estudantes ingressantes e concluintes que considerou que o acesso a cada uma das ações/serviços deveria ser "para ninguém", "para pobres" e "para todos". (Total de ingressantes $=216$. Total de concluintes = 133)

\begin{tabular}{|c|c|c|c|c|c|c|c|}
\hline \multirow[t]{2}{*}{ Serviços/ações } & \multicolumn{2}{|c|}{ Para Ninguém } & \multicolumn{2}{|c|}{ Para Pobres } & \multicolumn{3}{|c|}{ Para Todos } \\
\hline & Ingressantes & Concluintes & Ingressantes & Concluintes & Ingressantes & Concluintes & $p^{*}$ \\
\hline & $\%$ & $\%$ & $\%$ & $\%$ & $\%$ & $\%$ & \\
\hline $\begin{array}{l}\text { Acompanhamento de } \\
\text { pessoas com DCNT }\end{array}$ & 0,9 & 0,7 & 8,9 & 5,3 & 90,2 & 94,0 & 0,139 \\
\hline $\begin{array}{l}\text { Acompanhamento } \\
\text { Psicológico }\end{array}$ & 2,3 & 0,8 & 20,8 & 15,9 & 76,9 & 83,3 & 0,033 \\
\hline $\begin{array}{l}\text { Acompanhamento } \\
\text { gestante }\end{array}$ & 1 & 0,8 & 15,6 & 7,5 & 83,4 & 91,7 & 0,162 \\
\hline $\begin{array}{l}\text { Atendimento domiciliar } \\
\text { pessoas com dificuldade } \\
\text { locomoção }\end{array}$ & 0,5 & 1,5 & 25,5 & 18,0 & 74 & 80,5 & 0,045 \\
\hline
\end{tabular}




\begin{tabular}{|c|c|c|c|c|c|c|c|}
\hline $\begin{array}{l}\text { Atendimento } \\
\text { Odontológico }\end{array}$ & 2,3 & 0,8 & 35,0 & 26,3 & 62,7 & 72,9 & 0,155 \\
\hline Urgência e Emergência & 0,5 & 0,8 & 4,6 & 3,0 & 94,9 & 96,2 & 0,124 \\
\hline Fisioterapia & 2,8 & 0,8 & 39,0 & 29,3 & 58,2 & 69,9 & 0,440 \\
\hline $\begin{array}{l}\text { Fornecimento } \\
\text { Medicamento }\end{array}$ & 1,4 & 0,7 & 37,5 & 25,6 & 61,1 & 73,7 & 0,172 \\
\hline Programas de PCAF & 1,4 & 1,5 & 21,3 & 14,3 & 77,3 & 84,2 & 0,047 \\
\hline $\begin{array}{l}\text { Vacinação criança/ } \\
\text { adolescente }\end{array}$ & 0,5 & 0,7 & 6,9 & 3,8 & 92,6 & 95,5 & 0,221 \\
\hline Vacinação Adultos & 0,5 & 0,8 & 12,0 & 9,0 & 87,5 & 90,2 & 0,585 \\
\hline
\end{tabular}

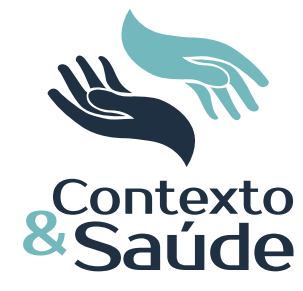

\section{DISCUSSÃO}

O objetivo desta pesquisa foi verificar a visão de estudantes do curso de Bacharelado em Educação Física de três universidades públicas do Paraná sobre como deveria ser o direito ao acesso ao SUS, de modo geral, e em serviços/ações específicos. Os principais resultados evidenciaram que, para a maioria $(85,4 \%)$ dos estudantes, o acesso ao SUS deve ser "para todos", independente da classe econômica ou social, sem diferença significativa entre ingressantes e concluintes. Apesar disso, quase $13 \%$ consideram que este acesso deve ser apenas para quem não pode pagar, ou seja, têm uma visão de SUS "para pobres". Quanto ao acesso de forma específica, os concluintes apresentaram mais respostas "para todos" sobre para quem deveria ser o acesso aos 11 serviços/ações oferecidos pelo SUS que os ingressantes.

A universalidade é o princípio do SUS que legalmente garante o acesso irrestrito aos serviços e ações de saúde para a população brasileira (GIOVANELLA et al., 2018). Os resultados da presente pesquisa mostram que os estudantes investigados, ao menos na questão mais genérica sobre o acesso ao SUS, parecem concordar com este princípio, uma vez que foi elevada a proporção dos que responderam que o acesso ao SUS deveria ser "para todos", não havendo diferença significativa nesta proporção entre ingressantes e concluintes.

Ainda assim, há de se considerar que quase $13 \%$ dos estudantes tenham respondido, na questão geral sobre acesso, que o Brasil "deveria ter serviços públicos de saúde para atender as pessoas que não podem pagar por atendimentos de saúde, enquanto as pessoas com condições financeiras deveriam pagar planos privados de saúde ou pagar individualmente pelos serviços de saúde", ou seja, acreditam que o acesso ao SUS deveria ser exclusivamente "para pobres". Este resultado reforça que talvez alguns estudantes tenham uma percepção 
estigmatizada sobre a utilização do SUS. Esta visão também foi encontrada em um estudo que observou que, mesmo para aqueles que tiveram uma boa experiência com os serviços públicos de saúde, o bom atendimento é relacionado à "sorte", e que os serviços públicos de saúde são direcionados àqueles que não podem pagar por serviços privados. Os autores do estudo citado concluíram que a utilização dos serviços do SUS está relacionada à sensação de vergonha e associada a um estigma social (REIGADA; ROMANO, 2018).

A visão de "SUS para pobres" vem sendo construída e sedimentada no imaginário da população de diversas maneiras. Seja por meio do teor e da forma negativa como são apresentadas as notícias na mídia a respeito dos serviços prestados pelo SUS, pelas forças políticas, por gestores e profissionais da área, ou pela expansão do capital financeiro, que pressiona os governos em todas as esferas a transformar cidadãos em consumidores e a saúde em mercadoria (PAIM, 2018; RIZZOTTO, 2018). Além disso, obstáculos à integração das redes de atenção à saúde acabam provocando dificuldades no atendimento à população, levando a falhas na integralidade do cuidado, invalidando a dimensão e a importância do sistema para a população (VASCONCELOS; PASCHE, 2006). Como obstáculos recentes podemos destacar o novo modelo de financiamento da Atenção Primária por meio do Programa Previne Brasil, que cancela os recursos advindos da União para os municípios (BRASIL, 2019), e a Nota Técnica no 3/2020, que deixa de credenciar novas equipes Nasf junto ao Ministério da Saúde (BRASIL, 2020b).

Um resultado que chamou a atenção se refere ao acesso às PCAFs, em que $21,3 \%$ dos ingressantes e $14,3 \%$ dos concluintes consideraram que o acesso deveria ser apenas para quem não pode pagar por serviços privados. Considerando que a amostra desta pesquisa foi formada por estudantes de Educação Física, que têm as PCAFs como seu objeto de estudo e atuação, este dado evidencia que ainda está presente a visão de que as PCAFs são uma "mercadoria" e não um fator condicionante e determinante de saúde, como aponta a lei brasileira (BRASIL, 2013). De qualquer modo, há de se ponderar que a inserção das PCAFs nas políticas públicas é relativamente recente, que o acesso a estes programas ainda é baixo e tem um alcance limitado entre a população, alcançando pessoas mais pobres e, principalmente, mulheres acima dos 50 anos, segundo Loch, Rodrigues e Teixeira (2013) e Ferreira et al. (2019). Apesar de estes programas terem atingido um perfil de pessoas que, historicamente, não tinham acesso às PCAFs (FERREIRA et al., 2019; LOCH; RODRIGUES; TEIXEIRA, 2013), não se pode ignorar que o acesso a estas práticas ainda é desigual, variando de acordo com o sexo, com as condições econômicas e de escolaridade, posto que os homens brancos, com maior escolaridade e renda, têm maior acesso às PCAFs no setor privado e tendem a ser mais ativos fisicamente do que pessoas mais pobres, não brancas e com menos anos de estudo (PNUD, 2017; ORLIZ; DUMITH; KNUTH, 2020).

Os resultados da presente pesquisa mostram a necessidade de a formação inicial de profissionais da Educação Física evidenciar a integralidade enquanto princípio finalístico do SUS. Se nem aqueles que têm a inserção de sua profissão no contexto do SUS justificadas pela integralidade tiverem uma visão que compreenda a importância deste princípio, inclusive para a prevenção de doenças e

Editora Unijuí - Revista Contexto \& Saúde - ISSN 2176-7114 - v. 21, n. 43, jul./set. 2021 
promoção da saúde, será mais difícil superar a ideia de um sistema público para pessoas pobres. Os resultados do estudo de Manske e Oliveira (2017) também indicam que o entendimento dos estudantes a respeito do SUS ainda se encontra frágil, e questionam se os cursos de Graduação têm oportunizado saberes e práticas suficientes sobre o SUS a estes futuros profissionais, pois essa fragilidade no conhecimento torna-se obstáculo para compreender as características que constituem o SUS e a atuação profissional na saúde pública, gerando resistência dos recém-formados aos progressos e evoluções tão necessários à saúde pública no Brasil.

Assim, é importante que os cursos de Graduação da área da saúde, não apenas da Educação Física, tenham conteúdos e experiências que proporcionem conhecimento acerca dos princípios do SUS, não somente para quem pretende atuar na saúde pública, mas também para aqueles que atuarão no contexto particular, pois este aprendizado ressalta pontos importantes, como a integralidade no cuidado e a humanização da assistência, além de contrapesar estruturas curriculares com o intuito de não priorizar o olhar biomédico em detrimento de outros aspectos importantes da vida, como o histórico, o econômico, o social e o cultural.

Uma das limitações desta pesquisa foi não ter coletado dados de estudantes do segundo e do terceiro anos. A intenção de coletar dados com ingressantes e concluintes foi verificar a visão que os estudantes têm do SUS ao iniciar a Graduação e, portanto, sem a influência das universidades no caso dos ingressantes, e analisar a visão que os alunos do último ano têm sobre o SUS após adquirirem conhecimentos e experiências proporcionadas pelas universidades em relação à saúde pública. Também não se obteve dados de estudantes de outros cursos de Graduação da área da saúde, pois a opção por estudar a visão de estudantes de Educação Física deveu-se pela recente inserção desta profissão no SUS. Outro ponto a ser destacado é relativo às perdas, mas há de se destacar, neste caso, que estas foram relativamente pequenas e que buscamos fazer um censo com os alunos ingressantes e concluintes das três universidades, não se usando técnicas de amostragem probabilísticas.

\section{CONSIDERAÇÕES FINAIS}

Não é tarefa simples mensurar o pensamento das pessoas sobre algo complexo, como a questão do direito ao acesso aos serviços de saúde, por isso há de se destacar o cuidado na construção do instrumento, que buscou avaliar a visão dos alunos sobre como deveria ser o acesso aos serviços de saúde. As questões foram desenvolvidas a partir do cumprimento de diferentes etapas até se chegar à versão final. Esta pesquisa, entretanto, não teve como objetivo estudar aspectos amplos, como o imaginário e a percepção dos indivíduos investigados a respeito do tema.

Os dados observados sobre a visão que os estudantes têm do acesso ao SUS, especialmente a visão sobre o acesso de maneira específica, podem demonstrar o quanto o conceito de mercantilização da saúde pode influenciar a visão que os futuros profissionais têm a respeito dos serviços que podem ser ofe-

Editora Unijuí - Revista Contexto \& Saúde - ISSN 2176-7114 - v. 21, n. 43, jul./set. 2021 
recidos na saúde pública, e também no modo como os egressos irão desenvolver sua prática profissional, pensando que a maneira de entender a complexidade do processo saúde-doença influenciará nas tomadas de decisão nos campos de trabalho.

\section{REFERÊNCIAS}

ANDRADE, D. R. Políticas recentes de promoção da atividade física no setor da saúde no Brasil. Rev. Corpoconsciência, Santo André, v. 15, n. 2, p. 2-6, jul./dez. 2011. Disponível em: https://edisciplinas.usp.br/pluginfile.php/5539165/mod_resource/content/0/Pol\%C3\%ADticas\%20Recentes\%20de\%20Promo\%C3\%A7\%C3\%A30\%20da\%20AF\%20no\%20 Brasil.pdf. Acesso em: 4 dez. 2020.

BRASIL. Lei ${ }^{\circ} 12.864$ de 24 de setembro de 2013. Altera o caput do art. 3o da Lei ${ }^{\circ}$ 8.080, de 19 de setembro de 1990, incluindo a atividade física como fator determinante e condicionante da saúde. Diário Oficinal da União, 24 set. 2013. Disponível em: http:// www.planalto.gov.br/ccivil_03/_ato2011-2014/2013/lei//12864.htm\#: :text=Altera\%20 ○\%20caput\%20do\%20art, determinante\%20e\%20condicionante\%20da\%20sa\%C3\%BAde.\&text $=2 \%$ C2\%BA\%20Esta\%20Lei\%20entra\%20em\%20vigor\%20na\%20data\%20 de\%20sua\%20publica\%C3\%A7\%C3\%A3o. Acesso em: 4 dez. 2020.

BRASIL. Ministério da Educação. Acesso à informação. Sistema de Regulação do Ensino Superior, e-MEC. 2020a. Disponível em: http://emec.mec.gov.br/emec/consulta-cadastro/detalhes-curso/d96957f455f6405d14c6542552b0f6eb/NTcx/9f1aa921d96ca1df24a34474cc171f61/MjE=. Acesso em: 25 fev. 2020.

BRASIL. Ministério da Saúde. Secretaria de Atenção Primária à Saúde. Departamento de Saúde da Família. Nota Técnica no3/2020, de 28 de janeiro de 2020b. Assunto: Núcleo Ampliado de Saúde da Família e Atenção Básica (NASF-AB) e Programa Previne Brasil. Disponivel em: https://www.conasems.org.br/wp-content/uploads/2020/01/NT-NASF-AB-e-Previne-Brasil-1.pdf. Acesso em: 10 fev. 2020.

BRASIL. Ministério da Saúde. Secretaria de Vigilância à Saúde. Secretaria de Atenção à Saúde. Política Nacional de Promoção da Saúde: PNPS: revisão da Portaria MS/GM no 687, de 30 de março de 2006. Brasília: Ministério da Saúde, 2014. Disponível em: http:// bvsms.saude.gov.br/bvs/publicacoes/politica_nacional_promocao_saude_pnaps.pdf. Acesso em: 4 dez. 2020.

BRASIL. Ministério da Saúde. Portaria no. 154 de 24 de janeiro de 2008. Cria os Núcleos de Apoio à Saúde da Família - Nasf. 24.01.2008. Disponível em: https://bvsms.saude.gov. br/bvs/saudelegis/gm/2008/prt0154_24_01_2008.html. Acesso em: 4 dez. 2020.

BRASIL. Ministério da Saúde. Portaria no 2.979 de 12 de novembro de 2019. Institui o Programa Previne Brasil, que estabelece novo modelo de financiamento de custeio da Atenção Primária à Saúde no âmbito do Sistema Único de Saúde, por meio da alteração da Portaria de Consolidação no 6/GM/MS, de 28 de setembro de 2017. Diário Oficial da União. 13.11.2019. Disponível em: https://www.in.gov.br/en/web/dou/-/portaria-n-2. 979-de-12-de-novembro-de-2019-227652180. Acesso em: 5 dez. 2020.

CANDIDO, L. O.; ROSSIT, R. A. S.; OLIVEIRA, R. C. Inserção profissional dos egressos de um curso de educação física com ênfase na formação em saúde. Trab. Educ. Saúde, Rio de Janeiro, v. 16, n. 1, p. 305-318, jan./abr. 2018. Disponível em: https://www.scielo.br/pdf/ tes/v16n1/1678-1007-tes-1981-7746-sol00096.pdf. Acesso em: 5 dez. 2020.

CNS. Conselho Nacional de Saúde. Resolução no 218, de 6 de março de 1997. Reconhece 13 categorias como profissionais de saúde de nível superior. Brasília, 1997. Disponível em: https://bvsms.saude.gov.br/bvs/saudelegis/cns/1997/res0218_06_03_1997.html. Acesso em: 5 dez. 2020.

COSTA, F. F. Novas diretrizes curriculares para os cursos de Graduação em Educação Física: oportunidades de aproximações com o SUS? Rev. Bras. Ativ. Fís. Saúde, Florianópolis, 24:e0067, 2019. Disponível em: https://rbafs.org.br/RBAFS/article/view/14098/10964. Acesso em: 5 dez. 2020.

Editora Unijuí - Revista Contexto \& Saúde - ISSN 2176-7114 - v. 21, n. 43, jul./set. 2021 
FERREIRA, R. W. et al. Acesso aos programas públicos de atividade física no Brasil: Pesquisa Nacional de Saúde 2013. Cad. Saúde Pública, Rio de Janeiro, v. 35, n. 2, e00008618, 2019. Disponível em: https://scielosp.org/pdf/csp/2019.v35n2/e00008618/pt. Acesso em: 5 dez. 2020.

GIOVANELLA, L. et al. Sistema universal de saúde e cobertura universal: desvendando pressupostos e estratégias. Ciên. Saúde Colet., Rio de Janeiro, v. 23, n. 6, p. 1.763-1.776. 2018.

GONÇALVES, L. Percepções sobre o sistema único de saúde em estudantes de bacharelado em educação fisica da Universidade Estadual de Londrina. 2016. Monografia - Universidade Estadual de Londrina, Londrina, 2016. 52 p.

LOCH, M. R.; RODRIGUES, C. G.; TEIXEIRA, D. C. E os homens? E os que moram longe? E os mais jovens? ...? Perfil dos usuários de programas de atividade física oferecidos pelas Unidades Básicas de Saúde de Londrina-PR. Rev. Bras. Cienc. Esporte, Porto Alegre, v. 35, n. 4, p. 947-961, 2013. Disponível em: https://www.scielo.br/pdf/rbce/v35n4/10.pdf. Acesso em: 5 dez. 2020.

LOCH, M. R. et al. As práticas corporais/atividade física nos 30 anos do Sistema Único de Saúde. Ciên. Saúde Colet., Rio de Janeiro, v. 23, n. 1, p. 3.469, 2018. Disponível em: https://www.scielo.br/pdf/csc/v23n10/1413-8123-csc-23-10-3469.pdf. Acesso em: 5 dez. 2020.

LOCH, M. R.; DIAS, D. F.; RECH, C. R. Apontamentos para a atuação do profissional de educação física na Atenção Básica à Saúde: um ensaio. Rev. Bras. Ativ. Fís. Saúde, Florianópolis, 24:e0069, 2019. Disponível em: https://rbafs.org.br/RBAFS/article/ view/13577/10958. Acesso em: 5 dez. 2020.

MANSKE, G. S.; OLIVEIRA, D. A formação do profissional de educação física e o Sistema Único de Saúde. Motrivivência, Florianópolis, v. 29, n. 52, p. 191-210, set. 2017. Disponível em: https://periodicos.ufsc.br/index.php/motrivivencia/article/view/2175-8042.2017v29n52p191/35039. Acesso em: 5 dez. 2020.

MARQUES, R. M. O direito à saúde no mundo. In: MARQUES, R. M.; PIOLA, S. F.; ROA, A. C. (org.). Sistema de saúde no Brasil: organização e financiamento. Rio de Janeiro: ABrES; Brasília: Ministério da Saúde; Departamento de Economia da Saúde, Investimentos e Desenvolvimento; Opas/OMS no Brasil, 2016. p. 11-36. Disponível em: http://bvsms.saude. gov.br/bvs/publicacoes/sistema_saude_brasil_organizacao_financiamento.pdf. Acesso em: 5 dez. 2020.

MINAYO, M. C. S. Contribuições da antropologia para pensar e fazer saúde. In: CAMPOS G. W. S.; MINAYO, M. C. S.; AKERMAN, M.; JÚNIOR, M. D.; CARVALHO, Y. M. (org.). Tratado de saúde coletiva. São Paulo: Hucitec; Rio de Janeiro: Ed. Fiocruz, 2006.

NEVES, R. L. R. et al. Educação Física na saúde pública: revisão sistemática. Rev. Bras. Ciên. e Mov., Brasília, v. 23, n. 2, p. 163-177, 2015. Disponível em: https://www.researchgate.net/publication/282522014_Educacao_Fisica_na_Saude_Publica_Revisao_Sistematica. Acesso em: 5 dez. 2020.

NOGUEIRA, J. A. D.; BOSI, M. L. M. Saúde coletiva e educação física: distanciamentos e interfaces. Ciên. Saúde Colet., Rio de Janeiro, v. 22, n. 6, p. 1.913-1.922. 2017. Disponível em: https://www.scielo.br/pdf/csc/v22n6/1413-8123-csc-22-06-1913.pdf. Acesso em: 5 dez. 2020.

NORONHA, J. C. Cobertura universal de saúde: como misturar conceitos, confundir objetivos, abandonar princípios. Cad. Saúde Pública, Rio de Janeiro, v. 29, n. 5, p. 847-849, maio 2013. Disponível em: https://www.scielo.br/pdf/csp/v29n5/03.pdf. Acesso em: 5 dez. 2020.

OLIVEIRA, R. C. Educação física, saúde e formação profissional. Physis. Rio de Janeiro, v. 28, n. 3, p. e280302, 2018. Disponível em: https://www.scielo.br/pdf/physis/v28n3/ 0103-7331-physis-28-03-e280302.pdf. Acesso em: 5 dez. 2020.

ORLIZ, M. M.; DUMITH, S. C.; KNUTH, A. G. Utilização de serviços de educação física por adultos e idosos no extremo sul do Brasil: estudo de base populacional. Ciên. Saúde Colet., Rio de Janeiro, v. 25, n. 2, p. 541-552, 2020. Disponível em: https://scielosp.org/article/csc/2020.v25n2/541-552/. Acesso em: 5 dez. 2020.

Editora Unijuí - Revista Contexto \& Saúde - ISSN 2176-7114 - v. 21, n. 43, jul./set. 2021 
PAIM, J. S. Sistema Único de Saúde (SUS) aos 30 anos. Ciên. Saúde Colet., Rio de Janeiro, v. 23, n. 6, p. 1.723-1.728, 2018.

PNUD. Programa das Nações Unidas para o Desenvolvimento. Movimento é vida! Atividades físicas e esportivas para todas as pessoas. Relatório Nacional de Desenvolvimento Humano do Brasil. 2017. Disponível em: http://movimentoevida.org/. Acesso em: 21 nov. 2019.

REIGADA, C. L. L.; ROMANO, V. F. O uso do SUS como estigma: a visão de uma classe média. Physis. Rio de Janeiro, v. 28, n. 3, p. e280316, 2018. Disponível em: https://www.scielo.br/pdf/physis/v28n3/0103-7331-physis-28-03-e280316.pdf. Acesso em: 5 dez. 2020.

RIZZOTTO, M. L. F. A reafirmação da democracia e do direito universal à saúde em tempos de ultra neoliberalismo. Ciên. Saúde Colet., Rio de Janeiro, v. 23, n. 6, p. 1.717-1.718, 2018.

UEL. Universidade Estadual de Londrina. Catálogo de cursos de Graduação - Educação Física Bacharelado. 2018. Disponível em: http://www.uel.br/prograd/?content=catalogo-cursos/catalogo_2018/cursos/educacao_fisica_bacharelado.html. Acesso em: 15 mar. 2019.

UNICENTRO. Universidade Estadual do Centro-Oeste. Educação Física/Guarapuava. Disponível em: https://www3.unicentro.br/cursos/educacao-fisica-guarapuava/. Acesso em: 15 mar. 2019.

VASCONCELOS, C. M.; PASCHE, D. F. Sistema Único de Saúde. In: CAMPOS, G. W. S.; MINAYO, M. C. S.; AKERMAN, M.; JÚNIOR, M. D.; CARVALHO, Y. M. (org.). Tratado de Saúde Coletiva. São Paulo: Hucitec; Rio de Janeiro: Ed. Fiocruz, 2006. 